\title{
Polymorphisms in HSD17B1 : Early Onset and Increased Risk of Alzheimer's Disease in Women with Down Syndrome
}

\author{
Joseph H. Lee, ${ }^{1,2,3}$ Susan Gurney, ${ }^{3}$ Deborah Pang, ${ }^{1,4}$ Alexis Temkin, ${ }^{5}$ \\ Naeun Park, ${ }^{1}$ Sarah C. Janicki, ${ }^{1,2,6}$ Warren B. Zigman, ${ }^{4}$ Wayne Silverman, ${ }^{7}$ \\ Benjamin Tycko, ${ }^{1,5}$ and Nicole Schupf ${ }^{1,3,8}$
}

\author{
${ }^{1}$ The Taub Institute for Research on Alzheimer's Disease and the Aging Brain, Columbia University Medical Center, \\ New York, NY 10032, USA \\ ${ }^{2}$ Gertrude H. Sergievsky Center, Columbia University Medical Center, New York, NY 10032, USA \\ ${ }^{3}$ Department of Epidemiology, Columbia University Medical Center, New York, NY 10032, USA \\ ${ }^{4}$ Department of Psychology, New York State Institute for Basic Research in Developmental Disabilities, Staten Island, \\ NY 10314, USA \\ ${ }^{5}$ Department of Pathology, Columbia University Medical Center, New York, NY 10032, USA \\ ${ }^{6}$ Department of Neurology, Columbia University Medical Center, New York, NY 10032, USA \\ ${ }^{7}$ Kennedy Krieger Institute and Johns Hopkins University School of Medicine, Baltimore, MD 21205, USA \\ ${ }^{8}$ Department of Psychiatry, Columbia University Medical Center, New York, NY 10032, USA
}

Correspondence should be addressed to Joseph H. Lee, JHL2@columbia.edu

Received 27 September 2011; Accepted 21 November 2011

Academic Editor: Elizabeth Head

Copyright (c) 2012 Joseph H. Lee et al. This is an open access article distributed under the Creative Commons Attribution License, which permits unrestricted use, distribution, and reproduction in any medium, provided the original work is properly cited.

\begin{abstract}
Background/Aims. Genetic variants that affect estrogen activity may influence the risk of Alzheimer's disease (AD). In women with Down syndrome, we examined the relation of polymorphisms in hydroxysteroid-17beta-dehydrogenase (HSD17B1) to age at onset and risk of AD. HSD17B1 encodes the enzyme 17 $\beta$-hydroxysteroid dehydrogenase (HSD1), which catalyzes the conversion of estrone to estradiol. Methods. Two hundred and thirty-eight women with DS, nondemented at baseline, 31-78 years of age, were followed at 14-18-month intervals for 4.5 years. Women were genotyped for 5 haplotype-tagging single-nucleotide polymorphisms (SNPs) in the HSD17B1 gene region, and their association with incident AD was examined. Results. Age at onset was earlier, and risk of AD was elevated from two- to threefold among women homozygous for the minor allele at 3 SNPs in intron 4 (rs676387), exon 6 (rs605059), and exon 4 in COASY (rs598126). Carriers of the haplotype TCC, based on the risk alleles for these three SNPs, had an almost twofold increased risk of developing $\mathrm{AD}$ (hazard ratio $=1.8,95 \% \mathrm{CI}, 1.1-3.1$ ). Conclusion. These findings support experimental and clinical studies of the neuroprotective role of estrogen.
\end{abstract}

\section{Introduction}

The neurotrophic and neuroprotective mechanisms of estrogen have beneficial effects on brain function that include increases in cholinergic activity [1-5], antioxidant activity [6, $7]$, and protection against the neurotoxic effects of beta amyloid [8-11]. Thus, the dramatic declines in estrogen following menopause may contribute to higher risk of $\mathrm{AD}$ in women [12].

Allelic variation in genes within the estrogen biosynthesis and estrogen receptor pathways may modify cerebral estro- gen activity and influence risk of $\mathrm{AD}$. The hydroxysteroid17beta-dehydrogenase (HSD17B1) gene, located on chromosome 17q11-q21, encodes the enzyme $17 \beta$-hydroxysteroid dehydrogenase (HSD1), which catalyzes the conversion of estrone to estradiol. Variants in HSD17B1 have been examined for their relation to hormone levels, $[13,14]$ breast cancer $[13,15-24]$, endometriosis and endometrial cancer [13, 25-29], colorectal cancer [30, 31], and prostate cancer [32], with inconsistent results. Studies of polymorphisms in HSD17B1 have focused on rs605059, a nonsynonymous single-nucleotide polymorphism in exon 6 . The T/C 
polymorphism in rs605059, the change in bases at codon 313 in exon 6, is expressed as the change in amino acids from serine to glycine. The rs605059 SER313GLY variant has been associated with a modestly increased risk of endometriosis, estrogen receptor-negative tumors in breast cancer patients, and colorectal cancer in women, conditions known to be associated with estrogen regulation $[16,28,29,31]$, but not all studies have found positive associations. Along with two other haplotype-tagged SNPs, (rs676387 and rs598126), these common variants represent over $80 \%$ of the variation at this locus. [13]. Expression of HSD17B1 was found to be increased in prefrontal cortex in late-stage $\mathrm{AD}$ [33], but variants in HSD17B1 have not been examined for their association with age at onset or risk of AD.

Women with Down syndrome (DS) are at high risk for $\mathrm{AD}$, with the onset of dementia 10-20 years earlier than women in the general population [34-36]. Early age at menopause and low levels of bioavailable estradiol in postmenopausal women with DS are both associated with earlier onset and increased cumulative incidence of $\mathrm{AD}[37,38]$, suggesting that the decline in estrogen contributes to pathological processes leading to AD in this high-risk population. In this study, we examined the relationships between singlenucleotide polymorphisms in $H S D 17 B 1$, age at onset, and cumulative incidence of $\mathrm{AD}$ in women with $\mathrm{DS}$ to determine if genotype was related to risk.

\section{Materials and Methods}

2.1. Subjects. The initial cohort included a community-based sample of 279 women with DS. Of these 279 women, 252 (90.3\%) agreed to provide a blood sample, and 244 (96.8\%) were genotyped for $H S D 17 B 1$. All individuals were 30 years of age or older at study onset and resided in New York, New Jersey, Pennsylvania, or Connecticut. In all cases, a family member or correspondent provided informed consent, including blood sampling and genotyping, with participants providing assent. The distribution of level of intellectual disability and residential placement did not differ between participants and those who did not participate. Recruitment, informed consent, and study procedures were approved by the Institutional Review Boards of Columbia University Medical Center and the New York State Institute for Basic Research in Developmental Disabilities.

2.2. Clinical Assessment. Assessments were repeated at 1418-month intervals over five cycles of data collection and included evaluations of cognition and functional abilities, behavioral/psychiatric conditions, and health status. Cognitive function was evaluated with a test battery designed for use with individuals with DS varying widely in their levels of intellectual functioning, as described previously [39]. Structured interviews were conducted with caregivers to collect information on changes in cognition, function, and adaptive behavior. Past and current medical records were reviewed for all participants using a standardized protocol.

2.3. Classification of Dementia. This is a longitudinal cohort study of onset of $\mathrm{AD}$ in women with Down syndrome. The classification of dementia status, dementia subtype, and age at onset was determined during consensus case conferences where information from all available sources was reviewed. Classifications were made blind to HSD17B1 genotype. We classified participants into two groups, following the recommendations of the AAMR-IASSID Working Group for the Establishment of Criteria for the Diagnosis of Dementia in Individuals with Developmental Disability [40]. Participants were classified as nondemented if they were without cognitive or functional decline, or if they showed some cognitive and/or functional decline that was not of significant magnitude to meet dementia criteria $(n=164)$. Participants were classified as demented if they showed substantial and consistent decline over the course of follow up for at least one-year duration and had no other medical or psychiatric conditions that might mimic dementia $(n=80)$. Age at meeting criteria for dementia was used to estimate age at the onset of dementia. Of the 80 participants with dementia, three had a history of stroke or TIA and were excluded from the analyses. Three additional participants were also excluded because their findings suggestive of dementia may have been caused by another non-AD medical or psychiatric condition, leaving 164 nondemented and 74 demented women in the analysis. Only women with probable or possible $\mathrm{AD}$ were included in the dementia group for analysis.

2.4. DNA Isolation and Genotyping. Genomic DNA was extracted from peripheral blood leukocytes using the FlexiGene DNA kit (Qiagen). Isolation of DNA and genotyping were performed blind to the dementia status of the participant. We analyzed 4 single-nucleotide polymorphisms (SNPs) in HSD17B1 and one flanking SNP (rs598126) in CoA synthase (COASY), which is in high-linkage disequilibrium with rs605059. These included rs605059 (SER313GLY, C > T), which has been the SNP most consistently and strongly associated with estrogen-related disorders. Additional tagging SNPS were selected to provide coverage of the gene or to include SNPs which had also been associated with estrogenrelated disorders in at least one study. These included rs2830 $(\mathrm{T}>\mathrm{C}), \mathrm{rs} 2676530(\mathrm{G}>\mathrm{A}), \operatorname{rs} 676387(\mathrm{G}>\mathrm{T})$, and rs598126 $(\mathrm{C}>\mathrm{T})$. Table 2 provides the locations and allele frequencies of these SNPs. SNPs were genotyped using TaqMan PCR assays (Applied Biosystems) with PCR cycling conditions recommended by the manufacturer, and by Prevention Genetics using proprietary array tape technology. Accuracy of the genotyping ( $\geq 97 \%$ ) was verified by including duplicate DNA samples by comparing the TaqMan and array tape data with results of restriction digestion polymorphisms (RFLPs) for several of the SNPs, and by testing for Hardy-Weinberg equilibrium. Not all genotypes were available for all women at all SNPs, so the numbers examined vary slightly by SNP.

2.5. Apolipoprotein E Genotypes. APOE genotyping was carried out by PCR/RFLP analysis using HhaI ( $C f o \mathrm{I}$ ) digestion of an $A P O E$ genomic PCR product spanning the polymorphic (cys/arg) sites at codons 112 and 158, followed by acrylamide gel electrophoresis to document the restriction fragment 
sizes [41]. Participants were classified according to the presence or absence of at least one APOE $\varepsilon 4$ allele.

2.6. Potential Confounders. Potential confounders included level of intellectual disability, body mass index (BMI), ethnicity, and the presence of an $A P O E \varepsilon 4$ allele. Level of intellectual disability was classified as mild to moderate (IQ from 35 to 70 ) or severe to profound (IQ < 34), based on IQ scores obtained before the onset of $\mathrm{AD}$. BMI was calculated as weight in kilograms divided by the squared height in square meters $\left(\mathrm{kg} / \mathrm{m}^{2}\right)$ and was measured at each evaluation. The baseline measure of BMI was used in the analysis and was included as a continuous variable. Ethnicity was categorized as white or nonwhite.

2.7. Statistical Analysis. Prior to association analysis, we tested all SNPs for Hardy-Weinberg Equilibrium using the HAPLOVIEW program [42], and all were found to be in Hardy-Weinberg equilibrium. SNPs were analyzed with a dominant model in which participants homozygous for the common allele were used as the reference group, with the exception of rs605059 and rs598126. We coded the C allele at rs605059 as the high-risk allele since previous work had shown that women carrying the C allele at rs605059 had lower levels of estradiol and a lower estradiol/estrone ratio than women carrying the TT genotype [13]. We coded the $\mathrm{C}$ allele as the high-risk allele in rs598126 since previous work had shown the TT genotype to be associated with increased risk of breast cancer [15]. To code the remaining genotypes, we used common alleles for HSD17B1 SNPs for Hapmap whites at the NCBI SNP web site (http://www.ncbi.nlm.nih.gov/projects/SNP/). In preliminary analyses, the $X^{2}$ test (or the Fisher's exact test when any cell had $<5$ subjects) was employed to assess the association between $\mathrm{AD}$ and SNP genotypes as well as other possible risk factors for $\mathrm{AD}$ including ethnicity, level of intellectual disability, and the presence of an APOE $\varepsilon 4$ allele. Analysis of variance (ANOVA) was used to examine BMI and age by $\mathrm{AD}$ status.

The analysis was structured as a longitudinal cohort study of the onset of AD. We used Cox proportional hazards modeling to assess the relationship between HSD17B1 genotypes, age at onset, cumulative incidence, and the hazard ratio of $\mathrm{AD}$, adjusting for ethnicity, $\mathrm{BMI}$, level of intellectual disability and the presence of an APOE $\varepsilon 4$ allele. The time to event variable was age at onset for participants who developed $\mathrm{AD}$ and age at last assessment for participants who remained nondemented throughout the follow-up period. Because a set of three contiguous SNPs that span $\sim 10 \mathrm{~kb}$ rs676387, rs605059, and rs598126 were significantly associated with $\mathrm{AD}$, we performed a haplotype analysis to identify haplotype(s) that may harbor a susceptibility variant(s) as implemented in the PLINK program [43]. For nearly all individuals, we were able to identify the most likely haplotypes from the genotype data with a high degree of certainty (i.e., the posterior probability approaching 1.0 for $91 \%$ of the cohort with the rest exceeding probability $>0.7$ ). Subsequently, we used the estimated haplotype as a "superlocus" (analogous to a microsatellite marker) to perform Cox
TABLE 1: Demographic characteristics.

\begin{tabular}{lcc}
\hline Characteristic & Nondemented & $\begin{array}{c}\text { Alzheimer's } \\
\text { disease }\end{array}$ \\
\hline$N$ & 164 & 74 \\
Age at baseline $(\mathrm{M}, \mathrm{SD})^{* *}$ & $47.3 \pm 6.9$ & $54.2 \pm 6.7$ \\
Level of intellectual disability $(n, \%)$ & & \\
$\quad$ Mild/moderate & $97(59.1)$ & $35(47.3)$ \\
$\quad$ Severe/profound & $67(40.9)$ & $39(52.7)$ \\
Ethnicity $(n, \%)$ & & \\
$\quad$ Non-hispanic white & $142(86.6)$ & $68(91.9)$ \\
$\quad$ Nonwhite & $22(13.4)$ & $6(8.1)$ \\
Body mass index $(\mathrm{M}, \mathrm{SD}) * *$ & $29.9 \pm 6.7$ & $28.0 \pm 6.0$ \\
Apolipoprotein E $\varepsilon 4$ allele $(n, \%)$ & $34(21.0)$ & $20(27.0)$ \\
\hline ** $P<0.05$. & &
\end{tabular}

proportional hazards modeling. We restricted the analysis to individuals with a posterior probability of carrying the haplotype of 1.0.

\section{Results}

3.1. Demographic Characteristics. The mean age of participants at baseline was 49.4 years (range 31.5 to 78.1 ), and 88 percent of the cohort were white. The mean length of follow-up was $4.5(\mathrm{SD} \pm 2.4)$ years. Table 1 presents the demographic characteristics of the participants according to $\mathrm{AD}$ status. Participants who developed AD over the follow-up period were significantly older at baseline than nondemented participants (54.2 versus 47.3 years) and were more likely to have severe or profound level of intellectual function (52.7\% versus $40.9 \%$ ), but did not differ in the distribution of ethnicity or the frequency of the APOE $\varepsilon 4$ allele. Women who developed AD had a significantly lower BMI at baseline than women who remained nondemented over the follow-up period. The mean age at onset of $\mathrm{AD}$ was $55.7 \pm 6.4$ years.

3.2. Analysis of SNPs in HSD17B1. Table 2 shows the locations and minor allele frequencies (MAFs) of HSD17B1 SNPs for Hapmap whites at the NCBI SNP web site (http:// www.ncbi.nlm.nih.gov/projects/SNP/) and for our cohort of women with DS. Allele frequencies were similar in women with DS to those observed in women without DS in the general population. Table 3 presents the distributions of HSD17B1 genotypes and the association between HSD17B1 SNPs and the hazard ratio of $\mathrm{AD}$ among women with Down syndrome, adjusted for age, ethnicity, level of intellectual disability, BMI, and the presence of an APOE $\varepsilon 4$ allele. All of the 5 SNPs examined were in high-linkage disequilibrium (LD > 0.9, Figure 3). Three SNPs, rs676387, rs605059, and rs598126, showed significant associations with $\mathrm{AD}$, the strongest being with rs605059. Women who carried one or two copies of the $\mathrm{T}$ allele at rs605059 were two to three times more likely to develop $\mathrm{AD}$ than women homozygous for the C allele ( $\mathrm{HR}=2.0,95 \% \mathrm{CI}, 0.98-4.2$ for those with the CT genotype and $\mathrm{HR}=3.0,95 \% \mathrm{CI}, 1.4-6.8$ for those with the TT genotype) (Table 3 ) and had both earlier onset and higher 
TABLE 2: HSD17B1 SNP chromosomal location ${ }^{\mathrm{a}}$.

\begin{tabular}{|c|c|c|c|c|c|c|}
\hline SNP & $\begin{array}{c}\text { Chromosome } \\
\text { position }^{\mathrm{a}}\end{array}$ & $\begin{array}{l}\text { Distance from } \\
\text { previous SNP }\end{array}$ & $\begin{array}{l}\text { Minor } \\
\text { allele }\end{array}$ & $\begin{array}{c}\text { MAF }^{\mathrm{b}} \\
\text { observed }\end{array}$ & $\begin{array}{l}\text { MAF from } \\
\text { NCBI* }^{*}\end{array}$ & $\begin{array}{c}\text { SNP location } \\
\text { relative to } \\
H S D 17 B 1\end{array}$ \\
\hline rs2830 & 37958089 & & $\mathrm{C}$ & 0.485 & .392 & Exon1 \\
\hline rs 2676530 & 37959481 & 1392 & A & 0.230 & .263 & Intron 4 \\
\hline rs676387 & 37959799 & 318 & $\mathrm{~T}$ & 0.259 & .337 & Intron 4 \\
\hline rs605059 & 37960432 & 633 & $\mathrm{~T}$ & 0.482 & .443 & Exon 6 \\
\hline rs598126 & 37970046 & 9614 & $\mathrm{~T}$ & 0.491 & .429 & $\begin{array}{c}\text { Exon } 4 \text { of } \\
\text { COASY }\end{array}$ \\
\hline
\end{tabular}

${ }^{a}$ Physical position on chromosome: Hg18, March 2006 assembly, dbSNP build 130.

${ }^{b}$ MAF: Minor allele frequency.

*http://www.ncbi.nlm.nih.gov/.

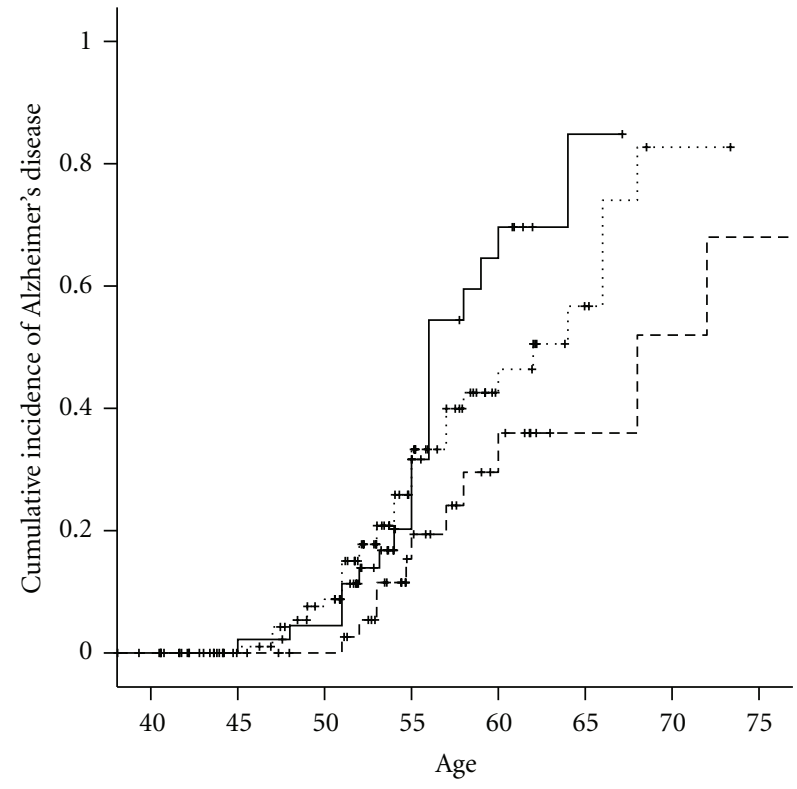

FIGURE 1: Cumulative incidence of Alzheimer's disease by HSD17B1 rs605059 genotype in women with Down syndrome. TT - - - . CT....... CC-.

cumulative incidence of $\mathrm{AD}$ over followup (Figure 1). The effects of carrying risk alleles for rs605059 were primarily seen in women over 60 years of age (Figure 1).

The relation of rs676387 and rs598126 to increased risk for $\mathrm{AD}$ was seen only among women homozygous for the risk allele (Table 3 ) and was associated to a two- and one halffold hazard ratio $\left(\mathrm{HR}_{\mathrm{r} 5676387}=2.7,95 \% \mathrm{CI}: 1.2-5.8\right.$ and $\left.\mathrm{HR}_{\mathrm{rs} 5998126}=2.2,95 \% \mathrm{CI}: 1.1-4.4\right)$ and with earlier onset but not higher cumulative incidence of AD (Figures 2(a) and 2(b)).

3.3. Haplotype Analysis of the Three SNPs in a Cox Proportional Hazards Modeling. We first computed the most likely haplotypes for each individual and then used the haplotypes as a "super locus" to estimate hazard ratios controlling for potential confounders. Our haplotype analysis using rs676387-rs605059-rs598126 revealed that the carriers of
TABLE 3: Alzheimer's disease risk by HSD17B1 genotype in women with Down syndrome.

\begin{tabular}{|c|c|c|c|}
\hline HSD17B1 genotype* & $N$ & $\mathrm{AD}$ & $\operatorname{HR}(95 \% \mathrm{CI})^{* *}$ \\
\hline \multicolumn{4}{|l|}{ rs2830 } \\
\hline CC & 49 & $15(30.6)$ & $0.7(0.3 .5)$ \\
\hline $\mathrm{CT}$ & 101 & $31(33.7)$ & $0.9(0.5-1.8)$ \\
\hline $\mathrm{TT}$ & 56 & $15(26.8)$ & 1.0 (reference) \\
\hline \multicolumn{4}{|l|}{ rs2676530 } \\
\hline $\mathrm{AA}$ & 14 & $7(50.0)$ & $1.5(0.7-3.3)$ \\
\hline $\mathrm{AG}$ & 75 & $17(22.7)$ & $0.7(0.4-1.2)$ \\
\hline GG & 135 & $47(34.8)$ & 1.0 (reference) \\
\hline \multicolumn{4}{|l|}{ rs676387 } \\
\hline TT & 22 & $9(40.9)$ & $2.7(1.2-5.8)$ \\
\hline GT & 72 & $23(31.9)$ & $1.4(0.8-2.4)$ \\
\hline GG & 129 & $40(31.0)$ & 1.0 (reference) \\
\hline \multicolumn{4}{|l|}{ rs605059 } \\
\hline CC & 59 & $20(33.9)$ & $3.0(1.4-6.8)$ \\
\hline $\mathrm{CT}$ & 107 & $34(31.8)$ & $2.0(0.98-4.2)$ \\
\hline TT & 51 & $12(23.5)$ & 1.0 (reference) \\
\hline \multicolumn{4}{|l|}{ rs598126 } \\
\hline CC & 58 & $15(34)$. & $2.2(1.1-4.4)$ \\
\hline $\mathrm{CT}$ & 119 & $37(31.1)$ & $1.4(0.7-2.6)$ \\
\hline TT & 54 & $20(27.8)$ & 1.0 (reference) \\
\hline
\end{tabular}

** Hazard ratio for $\mathrm{AD}$, adjusted for age, ethnicity, level of intellectual disability, BMI, and the presence of an APOE $\varepsilon 4$ allele.

* Numbers vary because not all participants were genotyped for all SNPs.

haplotype TCC had earlier onset of $\mathrm{AD}$, after adjusting for the presence of an APOE $\varepsilon 4$, allele level of intellectual disability, ethnicity, and BMI (hazard ratio $=1.8,95 \%$ CI, 1.13.1).

\section{Discussion}

Three of the five SNPs examined in HSD17B1 were associated with increased risk of $\mathrm{AD}$. Women who were heterozygous or homozygous for the $\mathrm{C}$ allele at rs605059 were two to three times as likely to develop AD as those carrying the TT 


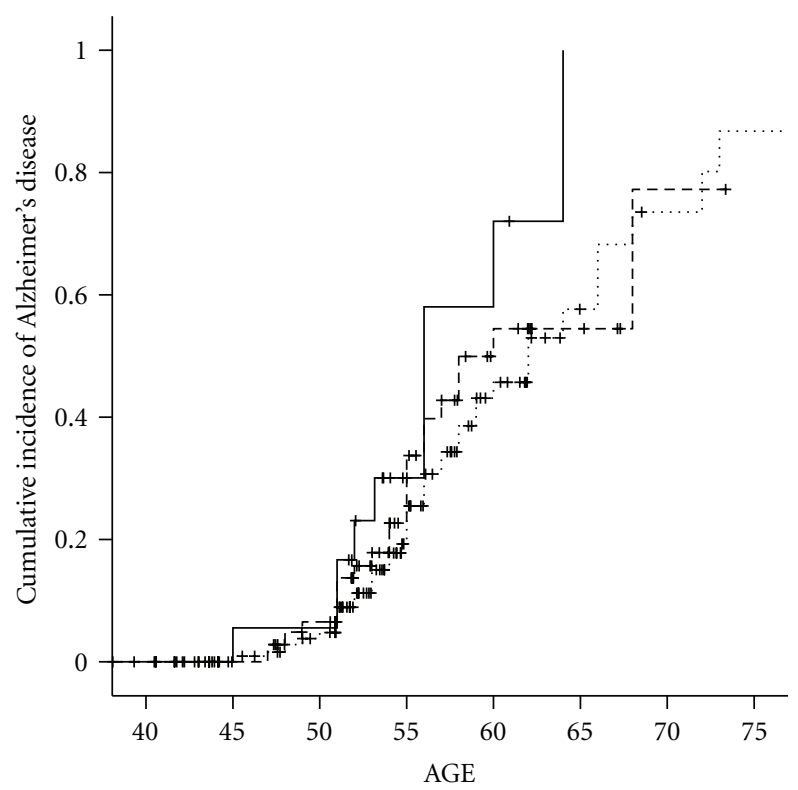

(a)

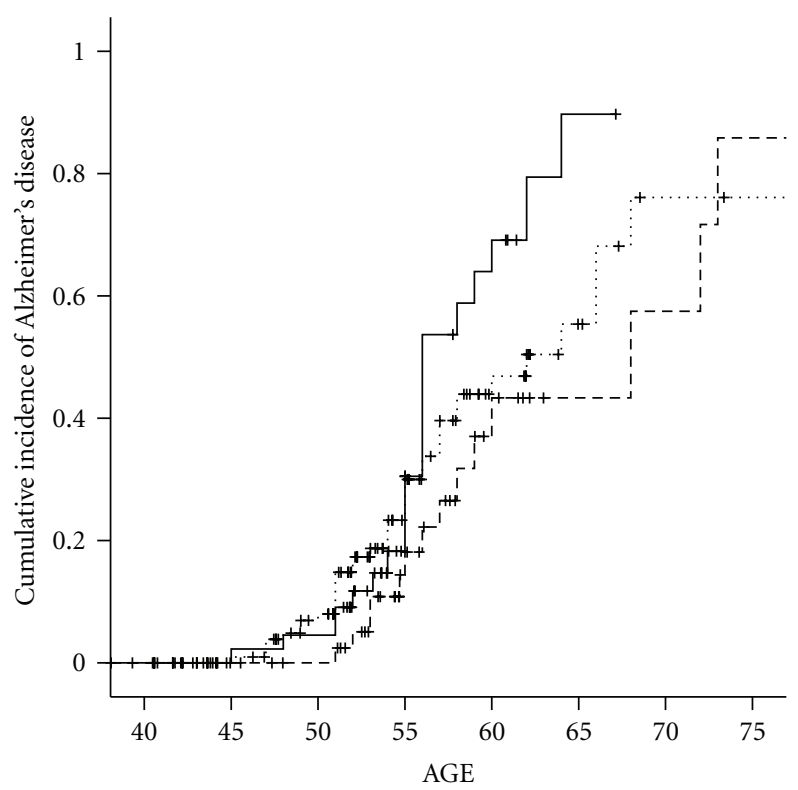

(b)

FIgURE 2: (a) Cumulative incidence of Alzheimer's disease by HSD17B1 rs598126 genotype in women with Down syndrome. TT - - - CT....... CC-. (b) Cumulative incidence of Alzheimer's disease by HSD17B1 rs676387 genotype in women with Down syndrome. CC - - - -. CT...... TT-.
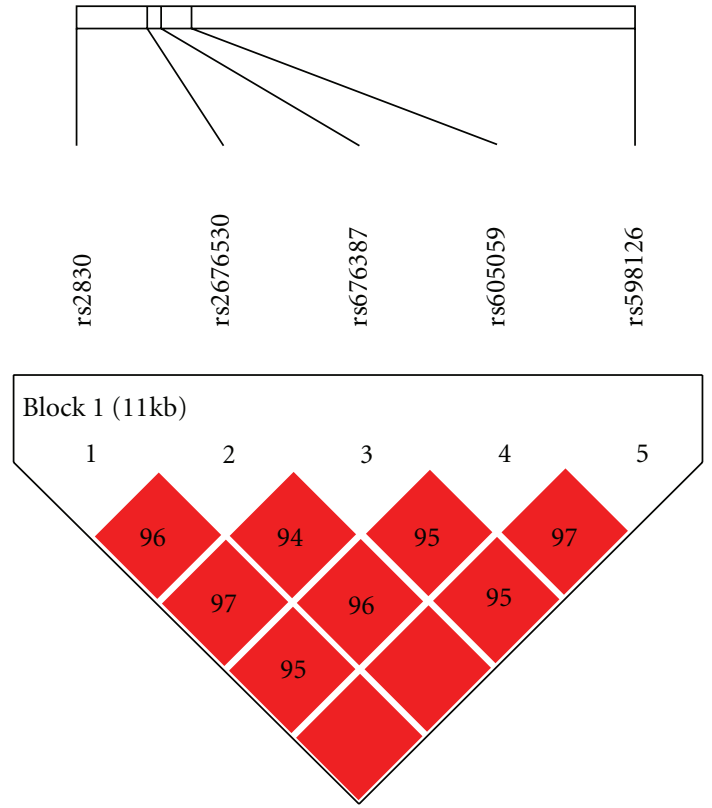

FIGURE 3: Linkage disequilibrium patterns for SNPs in HSD17B1.

genotype. Women with DS homozygous for the $\mathrm{T}$ allele at rs676387 or the $C$ allele at rs598126 had 2.7 and 2.2-fold increased risk of $\mathrm{AD}$, respectively, compared with women without these risk alleles, although risk was only slightly increased in women who were heterozygous for the risk allele. Carrying a high-risk allele at rs605059 was associated with both early onset and higher cumulative incidence, while carrying a high-risk allele at rs676387 or at rs598126 was associated primarily with earlier onset. Haplotype-based Cox proportional hazards model continued to support that TCC carriers had an almost 2-fold risk of developing AD after adjusting for covariates.

Polymorphisms or haplotypes in HSD17B1 have been associated with increased risk for estrogen receptor-negative breast cancer, endometriosis, and endometrial cancer, but these associations have been modest and inconsistent [13, 15-32]. The HSD17B1 gene encodes the enzyme HSD1 which catalyzes the conversion of estrone to estradiol. One pathway by which variants in $H S D 17 B 1$ could influence risk for $\mathrm{AD}$ is through changing the activity of HSD1 leading to changes in circulating estrogen levels. After menopause, the primary form of estrogen is estrone, which is formed in adipose tissue, muscle, liver, bone marrow, brain, and fibroblasts from aromatization of circulating androstenedione [44]. Increased body mass index in postmenopausal women is correlated with higher levels of serum estradiol and estrone $[45,46]$. Low BMI has been found to be a risk factor for cognitive decline and risk for $\mathrm{AD}$ in late life [39, 47-49], and BMI may decline decades before onset of AD [50]. Among postmenopausal women not using hormone replacement therapy, nonobese women (<25 BMI) who were heterozygous or homozygous for the $\mathrm{C}$ allele at rs605059 had lower levels of estradiol and a lower estradiol/estrone ratio than women carrying the TT genotype [13], while no corresponding effects on estrone or estradiol levels were seen in women with BMI $>25$. Our results showing earlier age at onset and higher cumulative incidence of $\mathrm{AD}$ among women carrying the $\mathrm{C}$ allele at rs605059 are consistent with this finding. Among non-obese women, variants in HSD17B1 have also been associated with a more rapid rate of decline in estradiol 
levels during the perimenopausal period [51]. Low estrogen levels have been associated with increased risk of cognitive impairment and $\mathrm{AD}[38,52-59]$, although some studies have found high levels of total estradiol in women with $\mathrm{AD}[60$, 61]. A role for low estrogen in $\mathrm{AD}$ has also been supported by experiments in which estrogen deficiency accelerated amyloid plaque formation in transgenic mouse models of $\mathrm{AD}$ $[62,63]$. The findings from this study are consistent with a role for HSD17B1 in modifying risk of AD through influences on peripheral or central estrogen levels and point to the potential for hormonal replacement therapy to delay onset of $\mathrm{AD}$ in this high-risk population.

HSD17B1 belongs to the family of short-chain dehydrogenases/reductases (SDRs) of which at least 11 other 17-beta HSD types are under study, named for their sequence homology to HSD17B1 [64]. One of these, 17-beta HSD10, has demonstrated involvement with $\mathrm{AD}$ through binding with amyloid-beta [65]. While the substrate activity of HSD17B1 is quite restricted, unlike that of 17beta HSD10, the multifunctionality of all SDRs is just beginning to be explored. For example, increased expression of HSD17B1 and aromatase have been found in the prefrontal cortex of $\mathrm{AD}$ patients during the later stages of the disease [33]. It has been suggested that estradiol is upregulated in astroglia during $\mathrm{AD}$, much as it is in reactive astroglia following brain injury, and increased expression of aromatase and HSD17B1 may determine differences in levels of protective neurosteroids in the prefrontal cortex [33]. Continued work on genetic factors affecting neurosteroid activity may help to understand differences in rates of cognitive aging and risk of dementia.

\section{Acknowledgments}

This work was supported by federal Grants AG014673 and HD035897 and by funds provided by New York State through its Office for People with Developmental Disabilities.

\section{References}

[1] V. N. Luine, "Estradiol increases choline acetyltransferase activity in specific basal forebrain nuclei and projection areas of female rats," Experimental Neurology, vol. 89, no. 2, pp. 484490, 1985.

[2] C. D. Toran-Allerand, R. C. Miranda, W. D. L. Bentham et al., "Estrogen receptors colocalize with low-affinity nerve growth factor receptors in cholinergic neurons of the basal forebrain," Proceedings of the National Academy of Sciences of the United States of America, vol. 89, no. 10, pp. 4668-4672, 1992.

[3] C. A. O’Malley, R. Dean Hautamaki, M. Kelley, and E. M. Meyer, "Effects of ovariectomy and estradiol benzoate on high affinity choline uptake, ACh synthesis, and release from rat cerebral cortical synaptosomes," Brain Research, vol. 403, no. 2, pp. 389-392, 1987.

[4] H. Yamamoto, J. Kitawaki, N. Kikuchi et al., "Effects of estrogens on cholinergic neurons in the rat basal nucleus," Journal of Steroid Biochemistry and Molecular Biology, vol. 107, no. 1-2, pp. 70-79, 2007.

[5] J. L. Spencer, E. M. Waters, R. D. Romeo, G. E. Wood, T. A. Milner, and B. S. McEwen, "Uncovering the mechanisms of estrogen effects on hippocampal function," Frontiers in Neuroendocrinology, vol. 29, no. 2, pp. 219-237, 2008.
[6] C. Behl, "Amyloid $\beta$-protein toxicity and oxidative stress in Alzheimer's disease," Cell and Tissue Research, vol. 290, no. 3, pp. 471-480, 1997.

[7] M. P. Mattson, N. Robinson, and Q. Guo, "Estrogens stabilize mitochondrial function and protect neural cells against the pro-apoptotic action of mutant presenilin-1," NeuroReport, vol. 8, no. 17, pp. 3817-3821, 1997.

[8] A. B. Jaffe, C. D. Toran-Allerand, P. Greengard, and S. E. Gandy, "Estrogen regulates metabolism of Alzheimer amyloid $\beta$ precursor protein," Journal of Biological Chemistry, vol. 269, no. 18, pp. 13065-13068, 1994.

[9] Y. Goodman, A. J. Bruce, B. Cheng, and M. P. Mattson, "Estrogens attenuate and corticosterone exacerbates excitotoxicity, oxidative injury, and amyloid $\beta$-peptide toxicity in hippocampal neurons," Journal of Neurochemistry, vol. 66, no. 5, pp. 1836-1844, 1996.

[10] S. Goodenough, M. Schäfer, and C. Behl, "Estrogen-induced cell signalling in a cellular model of Alzheimer's disease," Journal of Steroid Biochemistry and Molecular Biology, vol. 84, no. 2-3, pp. 301-305, 2003.

[11] H. Xu, R. Wang, Y.-W. Zhang, and X. Zhang, "Estrogen, $\beta$-amyloid metabolism/trafficking, and Alzheimer's disease," Annals of the New York Academy of Sciences, vol. 1089, pp. 324342, 2006.

[12] L. M. Garcia-Segura, I. Azcoitia, and L. L. DonCarlos, "Neuroprotection by estradiol," Progress in Neurobiology, vol. 63 , no. 1, pp. 29-60, 2001.

[13] V. W. Setiawan, S. E. Hankinson, G. A. Colditz, D. J. Hunter, and I. De Vivo, "HSD17B1 gene polymorphisms and risk of endometrial and breast cancer," Cancer Epidemiology Biomarkers and Prevention, vol. 13, no. 2, pp. 213-219, 2004.

[14] M. R. Sowers, S. Crawford, D. S. McConnell et al., "Selected diet and lifestyle factors are associated with estrogen metabolites in a multiracial/ethnic population of women," Journal of Nutrition, vol. 136, no. 6, pp. 1588-1595, 2006.

[15] H. S. Feigelson, D. G. Cox, H. M. Cann et al., "Haplotype analysis of the HSD17B1 gene and risk of breast cancer: a comprehensive approach to multicenter analyses of prospective cohort studies," Cancer Research, vol. 66, no. 4, pp. 2468-2475, 2006.

[16] H. S. Feigelson, R. McKean-Cowdin, G. A. Coetzee, D. O. Stram, L. N. Kolonel, and B. E. Henderson, "Building a multigenic model of breast cancer susceptibility: CYP17 and HSD17B1 are two important candidates," Cancer Research, vol. 61, no. 2, pp. 785-789, 2001.

[17] M. M. Gaudet, S. Chanock, A. Dunning et al., "HSD17B1 genetic variants and hormone receptor-defined breast cancer," Cancer Epidemiology Biomarkers and Prevention, vol. 17, no. 10, pp. 2766-2772, 2008.

[18] C. Justenhoven, U. Hamann, F. Schubert et al., "Breast cancer: a candidate gene approach across the estrogen metabolic pathway," Breast Cancer Research and Treatment, vol. 108, no. 1, pp. 137-149, 2008.

[19] E. Lee, F. Schumacher, J. P. Lewinger et al., "The association of polymorphisms in hormone metabolism pathway genes, menopausal hormone therapy, and breast cancer risk: a nested case-control study in the California Teachers Study cohort," Breast Cancer Research, vol. 13, no. 2, article R37, 2011.

[20] S. Sangrajrang, Y. Sato, H. Sakamoto et al., "Genetic polymorphisms of estrogen metabolizing enzyme and breast cancer risk in Thai women," International Journal of Cancer, vol. 125, no. 4, pp. 837-843, 2009. 
[21] S. N. Silva, M. N. Cabral, G. Bezerra de Castro et al., "Breast cancer risk and polymorphisms in genes involved in metabolism of estrogens (CYP17, HSD17beta1, COMT and $\mathrm{MnSOD}$ ): possible protective role of MnSOD gene polymorphism Val/Ala and Ala/Ala in women that never breast fed," Oncology reports, vol. 16, no. 4, pp. 781-788, 2006.

[22] Y. P. Wang, H. Li, J. Y. Li et al., "Relationship between estrogen-biosynthesis gene (CYP17, CYP19, HSD17beta1) polymorphisms and breast cancer," Zhonghua Zhong Liu Za Zhi, vol. 31, no. 12, pp. 899-903, 2009.

[23] A. H. Wu, A. Seow, K. Arakawa, D. Van Den Berg, H. P. Lee, and M. C. Yu, "HSD17B1 and CYP17 polymorphisms and breast cancer risk among Chinese women in Singapore," International Journal of Cancer, vol. 104, no. 4, pp. 450-457, 2003.

[24] M. Iwasaki, G. S. Hamada, I. N. Nishimoto et al., "Dietary isoflavone intake, polymorphisms in the CYP17, CYP19, 17HSD1, and SHBG genes, and risk of breast cancer in case-control studies in Japanese, Japanese Brazilians, and Non-Japanese Brazilians," Nutrition and Cancer, vol. 62, no. 4, pp. 466$475,2010$.

[25] K. A. Ashton, A. Proietto, G. Otton et al., "Polymorphisms in genes of the steroid hormone biosynthesis and metabolism pathways and endometrial cancer risk," Cancer Epidemiology, vol. 34, no. 3, pp. 328-337, 2010.

[26] A. Huber, C. C. Keck, L. A. Hefler et al., “Ten estrogen-related polymorphisms and endometriosis: a study of multiple genegene interactions," Obstetrics and Gynecology, vol. 106, no. 5, pp. 1025-1031, 2005.

[27] S. H. Olson, E. V. Bandera, and I. Orlow, "Variants in estrogen biosynthesis genes, sex steroid hormone levels, and endometrial cancer: a HuGE review," American Journal of Epidemiology, vol. 165, no. 3, pp. 235-245, 2007.

[28] M. Tsuchiya, H. Nakao, T. Katoh et al., "Association between endometriosis and genetic polymorphisms of the estradiolsynthesizing enzyme genes HSD17B1 and CYP19," Human Reproduction, vol. 20, no. 4, pp. 974-978, 2005.

[29] Q. Dai, W. H. Xu, J. R. Long et al., "Interaction of soy and $17 \beta$ HSD1 gene polymorphisms in the risk of endometrial cancer," Pharmacogenetics and Genomics, vol. 17, no. 2, pp. 161-167, 2007.

[30] J. H. Lin, J. E. Manson, P. Kraft et al., "Estrogen and progesterone-related gene variants and colorectal cancer risk in women," BMC Medical Genetics, vol. 12, article 78, 2011.

[31] J. Sainz, A. Rudolph, R. Hein et al., "Association of genetic polymorphisms in ESR2, HSD17B1, ABCB1, and SHBG genes with colorectal cancer risk," Endocrine-Related Cancer, vol. 18, no. 2, pp. 265-276, 2011.

[32] J. M. Cunningham, S. J. Hebbring, S. K. McDonnell et al., "Evaluation of genetic variations in the androgen and estrogen metabolic pathways as risk factors for sporadic and familial prostate cancer," Cancer Epidemiology Biomarkers and Prevention, vol. 16, no. 5, pp. 969-978, 2007.

[33] S. Luchetti, K. Bossers, S. Van de Bilt et al., "Neurosteroid biosynthetic pathways changes in prefrontal cortex in Alzheimer's disease," Neurobiology of Aging, vol. 32, no. 11, pp. 1964-1976, 2011.

[34] F. Lai and R. S. Williams, "A prospective study of Alzheimer disease in Down syndrome," Archives of Neurology, vol. 46, no. 8, pp. 849-853, 1989.

[35] W. B. Zigman, N. Schupf, E. Sersen, and W. Silverman, "Prevalence of dementia in adults with and without Down syndrome," American Journal on Mental Retardation, vol. 100, no. 4, pp. 403-412, 1996.
[36] D. M. A. Mann, "The pathological association between Down syndrome and Alzheimer disease," Mechanisms of Ageing and Development, vol. 43, no. 2, pp. 99-136, 1988.

[37] N. Schupf, D. Pang, B. N. Patel et al., "Onset of dementia is associated with age at menopause in women with Down's syndrome," Annals of Neurology, vol. 54, no. 4, pp. 433-438, 2003.

[38] N. Schupf, S. Winsten, B. Patel et al., "Bioavailable estradiol and age at onset of Alzheimer's disease in postmenopausal women with Down syndrome," Neuroscience Letters, vol. 406, no. 3, pp. 298-302, 2006.

[39] B. N. Patel, D. Pang, Y. Stern et al., "Obesity enhances verbal memory in postmenopausal women with Down syndrome," Neurobiology of Aging, vol. 25, no. 2, pp. 159-166, 2004.

[40] E. H. Aylward, D. B. Burt, L. U. Thorpe, F. Lai, and A. Dalton, "Diagnosis of dementia in individuals with intellectual disability," Journal of Intellectual Disability Research, vol. 41, no. 2, pp. 152-164, 1997.

[41] J. E. Hixson and D. T. Vernier, "Restriction isotyping of human apolipoprotein $\mathrm{E}$ by gene amplification and cleavage with HhaI," Journal of Lipid Research, vol. 31, no. 3, pp. 545-548, 1990.

[42] J. C. Barrett, B. Fry, J. Maller, and M. J. Daly, "Haploview: analysis and visualization of LD and haplotype maps," Bioinformatics, vol. 21, no. 2, pp. 263-265, 2005.

[43] S. Purcell, B. Neale, K. Todd-Brown et al., "PLINK: a tool set for whole-genome association and population-based linkage analyses," American Journal of Human Genetics, vol. 81, no. 3, pp. 559-575, 2007.

[44] H. L. Judd, I. M. Shamonki, A. M. Frumar, and L. D. Lagasse, "Origin of serum estradiol in postmenopausal women," Obstetrics and Gynecology, vol. 59, no. 6, pp. 680-686, 1982.

[45] J. A. Cauley, J. P. Gutai, L. H. Kuller, D. LeDonne, and J. G. Powell, "The epidemiology of serum sex hormones in postmenopausal women," American Journal of Epidemiology, vol. 129, no. 6, pp. 1120-1131, 1989.

[46] D. R. Meldrum, B. J. Davidson, I. V. Tataryn, and H. L. Judd, "Changes in circulating steroids with aging in postmenopausal women," Obstetrics and Gynecology, vol. 57, no. 5, pp. 624-628, 1981.

[47] T. F. Hughes, A. R. Borenstein, E. Schofield, Y. Wu, and E. B. Larson, "Association between late-life body mass index and dementia The Kame Project," Neurology, vol. 72, no. 20, pp. 1741-1746, 2009.

[48] A. L. Fitzpatrick, L. H. Kuller, O. L. Lopez et al., "Midlife and late-life obesity and the risk of dementia: cardiovascular health study," Archives of Neurology, vol. 66, no. 3, pp. 336-342, 2009.

[49] J. A. Luchsinger and D. R. Gustafson, "Adiposity and Alzheimer's disease," Current Opinion in Clinical Nutrition and Metabolic Care, vol. 12, no. 1, pp. 15-21, 2009.

[50] D. S. Knopman, S. D. Edland, R. H. Cha, R. C. Petersen, and W. A. Rocca, "Incident dementia in women is preceded by weight loss by at least a decade," Neurology, vol. 69, no. 8, pp. 739-746, 2007.

[51] M. R. Sowers, J. F. Randolph, H. Zheng et al., "Genetic polymorphisms and obesity influence estradiol decline during the menopause," Clinical Endocrinology, vol. 74, no. 5, pp. 618623, 2011.

[52] K. Yaffe, D. Grady, A. Pressman, and S. Cummings, "Serum estrogen levels, cognitive performance, and risk of cognitive decline in older community women," Journal of the American Geriatrics Society, vol. 46, no. 7, pp. 816-821, 1998. 
[53] K. Yaffe, L. Y. Lui, D. Grady, J. Cauley, J. Kramer, and S. R. Cummings, "Cognitive decline in women in relation to nonprotein-bound oestradiol concentrations," Lancet, vol. 356, no. 9231, pp. 708-712, 2000.

[54] J. J. Manly, C. A. Merchant, D. M. Jacobs et al., "Endogenous estrogen levels and Alzheimer's disease among postmenopausal women," Neurology, vol. 54, no. 4, pp. 833-837, 2000.

[55] E. K. Hoskin, M. X. Tang, J. J. Manly, and R. Mayeux, "Elevated sex-hormone binding globulin in elderly women with Alzheimer's disease," Neurobiology of Aging, vol. 25, no. 2, pp. 141-147, 2004.

[56] J. G. Buckwalter, L. S. Schneider, T. W. Wilshire, M. E. Dunn, and V. W. Henderson, "Body weight, estrogen and cognitive functioning in Alzheimer's disease: an analysis of the Tacrine Study Group Data," Archives of Gerontology and Geriatrics, vol. 24, no. 3, pp. 261-267, 1997.

[57] E. B. Drake, V. W. Henderson, F. Z. Stanczyk et al., "Associations between circulating sex steroid hormones and cognition in normal elderly women," Neurology, vol. 54, no. 3, pp. 599603, 2000.

[58] K. Yaffe, D. Barnes, K. Lindquist et al., "Endogenous sex hormone levels and risk of cognitive decline in an older biracial cohort," Neurobiology of Aging, vol. 28, no. 2, pp. 171-178, 2007.

[59] M. Muller, N. Schupf, J. J. Manly, R. Mayeux, and J. A. Luchsinger, "Sex hormone binding globulin and incident Alzheimer's disease in elderly men and women," Neurobiology of Aging, vol. 31, no. 10, pp. 1758-1765, 2010.

[60] E. Hogervosrt and A. D. Smith, "The interaction of serum folate and estradiol levels in Alzheimer's disease," Neuroendocrinology Letters, vol. 23, no. 2, pp. 155-160, 2002.

[61] E. Hogervorst, J. Williams, M. Combrinck, and A. D. Smith, "Measuring serum oestradiol in women with Alzheimer's disease: the importance of the sensitivity of the assay method," European Journal of Endocrinology, vol. 148, no. 1, pp. 67-72, 2003.

[62] X. Yue, M. Lu, T. Lancaster et al., "Brain estrogen deficiency accelerates $\mathrm{A} \beta$ plaque formation in an Alzheimer's disease animal model," Proceedings of the National Academy of Sciences of the United States of America, vol. 102, no. 52, pp. 19198-19203, 2005.

[63] J. C. Carroll, E. R. Rosario, L. Chang et al., "Progesterone and estrogen regulate Alzheimer-like neuropathology in female 3xTg-AD mice," Journal of Neuroscience, vol. 27, no. 48, pp. 13357-13365, 2007.

[64] G. Moeller and J. Adamski, "Multifunctionality of human $17 \beta$ hydroxysteroid dehydrogenases," Molecular and Cellular Endocrinology, vol. 248, no. 1-2, pp. 47-55, 2006.

[65] S.-Y. Yang, X.-Y. He, and H. Schulz, "Multiple functions of type $1017 \beta$-hydroxysteroid dehydrogenase," Trends in Endocrinology and Metabolism, vol. 16, no. 4, pp. 167-175, 2005. 


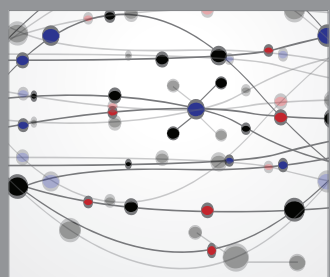

The Scientific World Journal
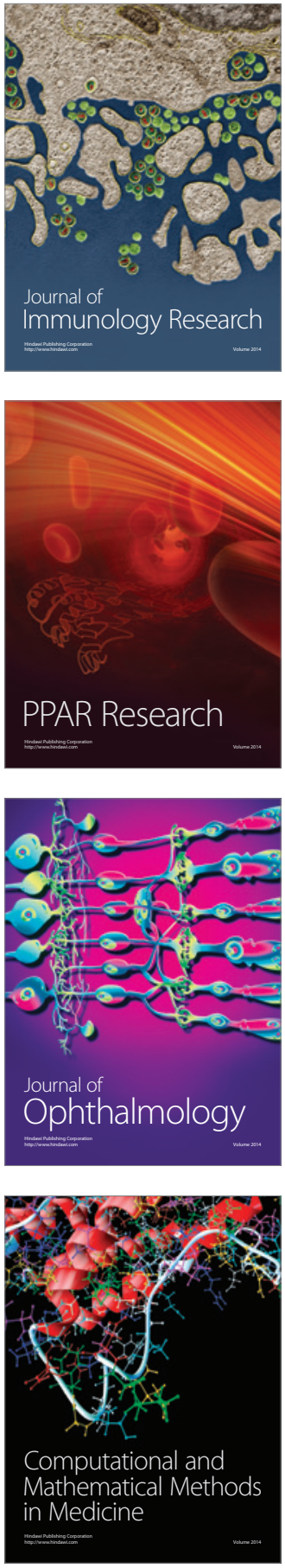

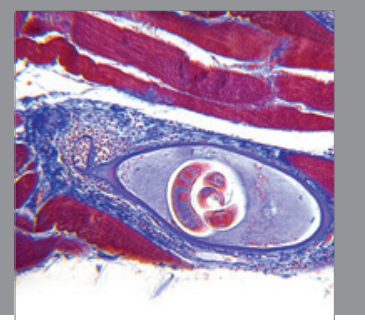

Gastroenterology

Research and Practice
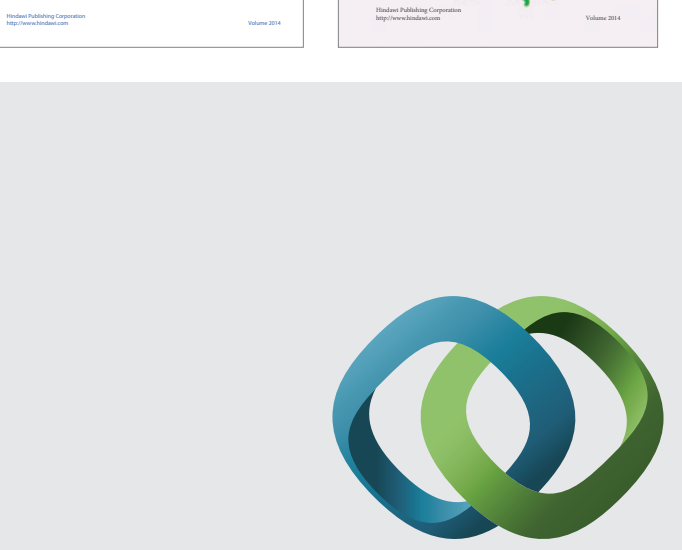

\section{Hindawi}

Submit your manuscripts at

http://www.hindawi.com
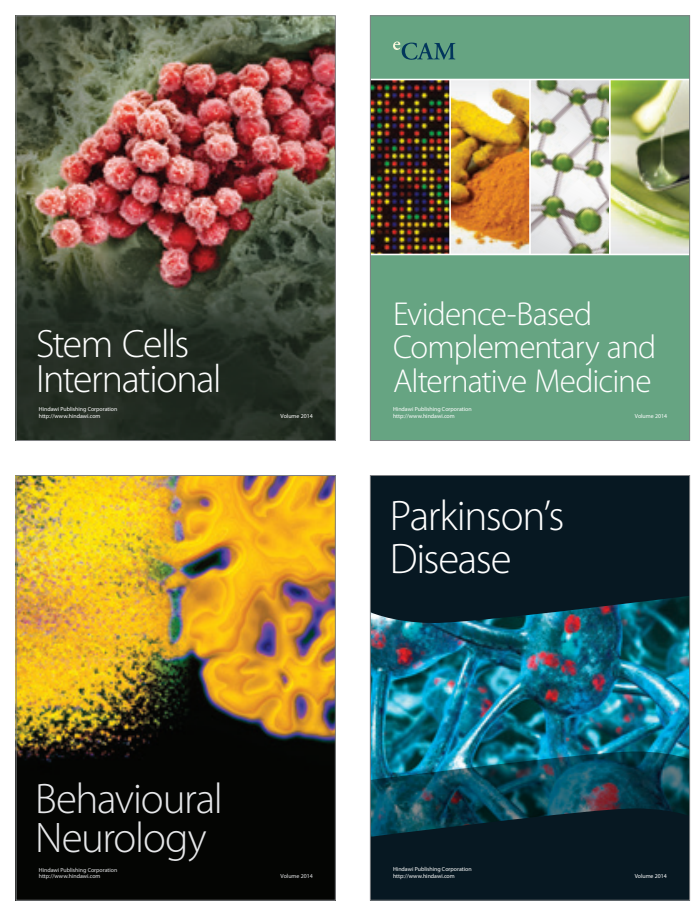

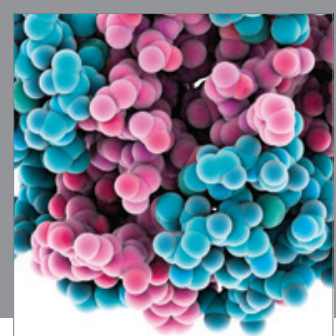

Journal of
Diabetes Research

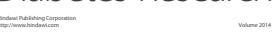

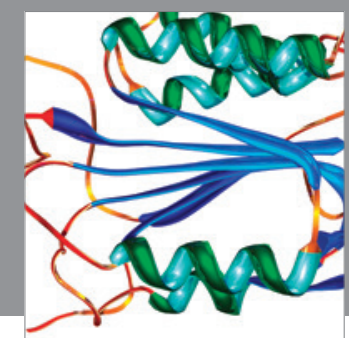

Disease Markers
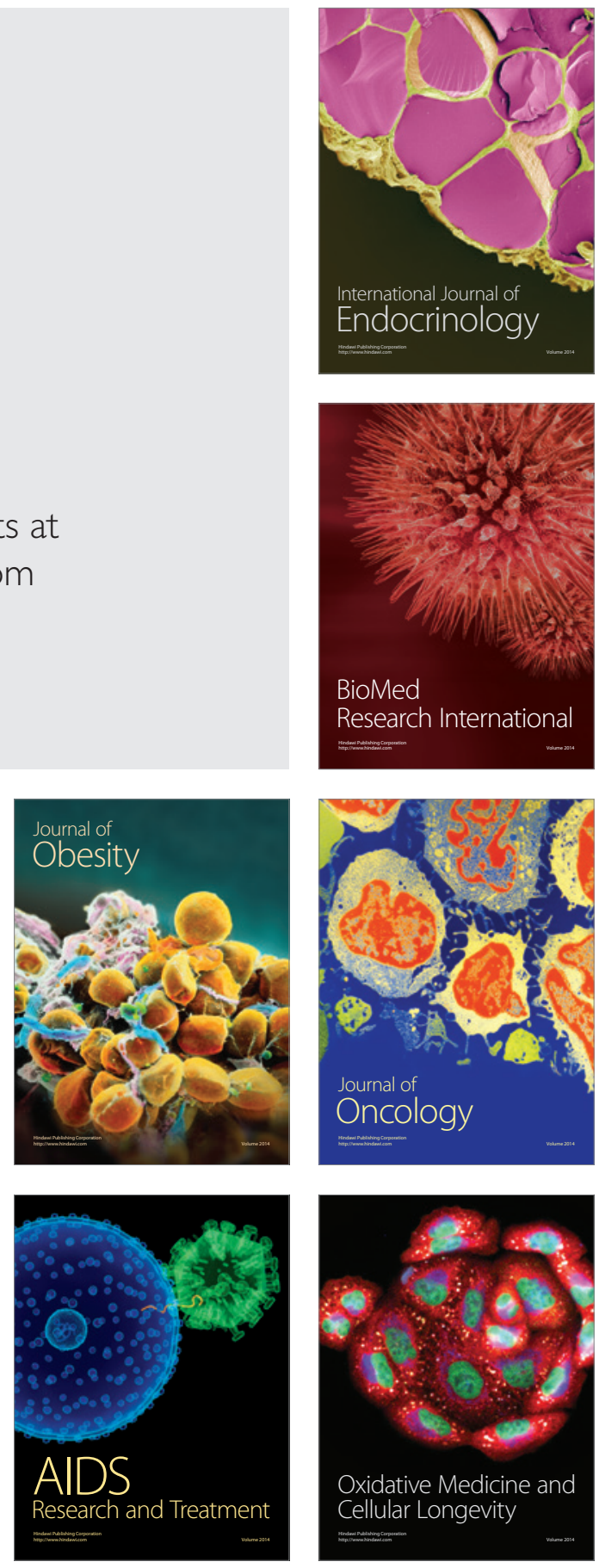